\title{
Prediction of peak expiratory flow rate in a Ugandan population
}

\author{
S Nakubulwa, ${ }^{1} \mathrm{MSc} ; \mathrm{K}$ Baisley, ${ }^{2} \mathrm{MSc} ; \mathrm{J}$ Levin, ${ }^{3} \mathrm{PhD} ; \mathrm{J}$ Nakiyingi-Miiro, ${ }^{1} \mathrm{PhD} ;$ A Kamali, ${ }^{1} \mathrm{PhD} ;$ A Nunn, ${ }^{4} \mathrm{MSc}$ \\ ${ }^{1}$ Medical Research Council/Uganda Research Unit on AIDS, Entebbe, Uganda \\ ${ }^{2}$ London School of Hygiene and Tropical Medicine, London, UK \\ ${ }^{3}$ School of Public Health, Faculty of Health Sciences, University of the Witwatersrand, Johannesburg, South Africa \\ ${ }^{4}$ Medical Research Council Clinical Trials Unit, University College London, UK
}

Corresponding author: A Nunn (andrew.nunn@ucl.ac.uk)

Background. Peak expiratory flow rate (PEFR) measurement is one of the commonly used methods for assessing lung function in general practice consultations. The reference values for use by this method are mainly from Caucasian populations; data for African populations are limited. The existence of ethnic and racial differences in lung function necessitates further generation of PEFR reference values for use in African populations. Objective. To generate equations for predicting PEFR in a Ugandan population.

Methods. The PEFR study was cross-sectional and based in rural south-western Uganda. Participants were aged 15 years or more, without respiratory symptoms and were residents of the study area. Multiple regression equations for predicting PEFR were fitted separately for males and females. The model used for PEFR prediction was: $\log _{\mathrm{e}} \mathrm{PEFR}=$ intercept $+\mathrm{a}(\mathrm{age}, \mathrm{y})+\mathrm{b}\left(\log _{\mathrm{e}} \mathrm{gge}\right)+\mathrm{c}(1 /$ height in $\mathrm{cm})$, where $\mathrm{a}, \mathrm{b}$ and $\mathrm{c}$ are the regression coefficients. Results. The eligible study population consisted of 774 males and 781 females. Median height was $164 \mathrm{~cm}$ (males) and $155 \mathrm{~cm}$ (females). The majority of participants had never smoked (males $76.7 \%$; females $98.3 \%$ ). The equation which gave the best fit for males was $\log _{\mathrm{e}} \mathrm{PEFR}=6.188-0.019$ age $+0.557 \log _{\mathrm{e}}$ age $-199.945 /$ height and for females: $\log _{\mathrm{e}}$ PEFR $=5.948-0.014$ age $+0.317 \log _{\mathrm{e}}$ age $-85.147 /$ height Conclusion. The curvilinear model obtained takes into consideration the changing trends of PEFR with increasing age from adolescence to old age. It provides PEFR prediction equations that can be applied in East African populations.

S Afr Respir J 2015;21(4):96-99. DOI:10.7196/SARJ.2015.v21i4.36

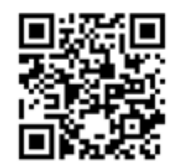

Pulmonary function tests play an important role in medicine by enabling the detection of airway obstruction, lung disease and its severity. ${ }^{[1]}$ The methods for the testing include peak expiratory flow rate (PEFR), forced expiratory value in 1 second $\left(\mathrm{FEV}_{1}\right)$ and forced vital capacity (FVC). ${ }^{[2]}$ PEFR, the maximum flow of air during a forceful exhalation, is one of the most widely used tests for assessing lung function in epidemiological surveys and is commonly used in general practice consultations. ${ }^{[2,3]}$ It is cheap, easy to use and does not require an electrical power supply. It is therefore convenient for use in resource-limited settings and in field studies. ${ }^{[3-5]}$

Appropriate normal reference values for different populations are needed during the assessment of pulmonary function. ${ }^{[2]}$ Studies have been conducted to develop prediction equations that can be used globally to obtain normal reference values; however, the data on which these equations are based are mostly from Caucasian populations, and data for African settings are limited. ${ }^{[1,6,7]}$ These existing prediction equations may overestimate PEFR in black Africans by $12-15 \% \cdot{ }^{[3]}$ Recognised ethnic and racial differences in lung function argue for the development of PEFR prediction equations for use in African populations. ${ }^{[8,9]}$

Of the few studies on PEFR prediction equations that have been conducted in African populations, some have assumed a linear relationship between PEFR and age, not taking account of the increase in lung function during adolescence before a subsequent decline in later life. A study in Sudanese, South Sudanese and Tanzanian males showed a decline in PEFR from 17 to 70 years of age. ${ }^{[10]}$ This finding differed from that of a study in Nigeria, where the decline in PEFR started at 30 years for males. ${ }^{[3]}$

The available data would suggest that a linear fall in PEFR occurs from an age in the late 20 s after maximal PEFR has been attained. ${ }^{[11,12]}$ The objective of this study, therefore, was to obtain regression equations for predicting PEFR in an African population, using a curvilinear model that considers changing trends of PEFR with age, given the fact that there are limited data on this topic in Africa.

\section{Methods}

Study design

This was a cross-sectional study in which measurements of PEFR were obtained during a 1994/1995 survey of a general population cohort (GPC) in Uganda. Data were also collected on sociodemographic factors, general health and HIV status.

\section{Study population}

In 1989/1990, the GPC was set up by the Medical Research Council/ Uganda Virus Research Institute (MRC/UVRI) Unit on AIDS to study the dynamics of HIV-1 infection in a rural African population. Census, socioeconomic and medical surveys have been conducted annually until the present time. During the time of the PEFR survey, the cohort comprised all residents in 15 villages in the subcounty of Kyamulibwa, a rural area in south-western Uganda, about $40 \mathrm{~km}$ from Lake Victoria. The study population consisted of mainly subsistence farmers, whose staple diet was matooke (cooked bananas) with groundnuts. More details of the cohort have been published elsewhere. ${ }^{[13,14]}$

In each annual medical survey, all adults aged $\geq 13$ years are invited to participate; the survey includes determination of HIV-serostatus and other health indicators. During the 1994/1995 survey, participants had their PEFR function measured to construct a prediction model for an East African population and assess factors related to subnormal PEFR.

\section{PEFR measurements}

PEFR measurements were performed using mini Wright flow meters, which were calibrated at regular intervals. Participants were asked to 
make three attempts, and if readings were unsatisfactory, two further attempts were made. Measurements were recorded to the nearest $10 \mathrm{~L} / \mathrm{min}$. The maximum of these attempts was recorded as the observed PEFR. Measurements were made with participants in standing position.

Data management and statistical analysis

Data were entered by two independent operators using dBase III+ software (Ashton-Tate, USA). Data were analysed with Stata version 11.0 (Stata Corp., USA).

Demographic characteristics of the 1994/95 survey participants were compared with those of the larger population that took part in the census, to assess whether the sample from which the PEFR data were collected was representative of the population.

Multiple regression equations were fitted separately for males and females for predicting PEFR as follows: $\log _{\mathrm{e}}$ PEFR $=$ intercept + $\mathrm{a}($ age, $\mathrm{y})+\mathrm{b}\left(\log _{\mathrm{e}} \mathrm{age}\right)+\mathrm{c}(1 /$ height in $\mathrm{cm})$, where $\mathrm{a}, \mathrm{b}$ and $\mathrm{c}$ were the regression coefficients.

\section{Table 1. Characteristics of the study population}

\begin{tabular}{|c|c|c|}
\hline Variable & $\begin{array}{l}\text { Males }(N=774), \\
n(\%)\end{array}$ & $\begin{array}{l}\text { Females }(N=781), \\
n(\%)\end{array}$ \\
\hline \multicolumn{3}{|l|}{ Age group (years) } \\
\hline $15-24$ & $351(45.4)$ & $314(40.2)$ \\
\hline $25-34$ & $165(21.3)$ & $156(20.0)$ \\
\hline $35-44$ & $86(11.1)$ & $123(15.8)$ \\
\hline $45-54$ & $53(6.9)$ & $90(11.5)$ \\
\hline $55-64$ & $55(7.1)$ & $62(7.9)$ \\
\hline $65+$ & $64(8.3)$ & $36(4.6)$ \\
\hline Median (IQR) & $26(18-42)$ & $29(19-43)$ \\
\hline Height $(\mathrm{cm})$, median (IQR) & $164(157-168)$ & $155(151-159)$ \\
\hline \multicolumn{3}{|l|}{ Indoor cooking $(N=1535)$} \\
\hline Never & $667(87.4)$ & $700(90.7)$ \\
\hline Sometimes & $22(2.9)$ & $35(4.5)$ \\
\hline Always & $74(9.7)$ & $37(4.8)$ \\
\hline \multicolumn{3}{|l|}{ HIV status ( $N=1547)$} \\
\hline Negative & $736(96.0)$ & $736(94.4)$ \\
\hline Positive & $31(4.0)$ & $44(5.6)$ \\
\hline \multicolumn{3}{|l|}{ Smoking $(N=1517)$} \\
\hline Never smoked & $565(76.7)$ & $767(98.3)$ \\
\hline Stopped smoking & $31(4.2)$ & $2(0.3)$ \\
\hline Smoke now & $141(19.1)$ & $11(1.4)$ \\
\hline \multicolumn{3}{|l|}{ Marital status $(N=1439)$} \\
\hline Currently married & $330(45.7)$ & $359(50.1)$ \\
\hline Never married & $341(47.2)$ & $215(30.0)$ \\
\hline Widowed & $8(1.1)$ & $61(8.5)$ \\
\hline Divorced & $43(6.0)$ & $82(11.4)$ \\
\hline \multicolumn{3}{|l|}{ Floor material $(N=1530)$} \\
\hline Cement & $90(11.8)$ & $125(16.2)$ \\
\hline Cow dung & $6(0.8)$ & $4(0.5)$ \\
\hline Ordinary murram & $664(87.4)$ & $641(83.3)$ \\
\hline
\end{tabular}

The model was adapted from a study in the UK by Nunn and Gregg, ${ }^{[12]}$ which did not assume a linear relationship between age and PEFR but allowed for the fact that PEFR initially increases with age before reaching a maximum, after which it declines.

Observed PEFR in males and females was plotted separately against age. The regressions of PEFR on age using median height (calculated separately for males and females) were obtained from the equations generated in this study and were graphically presented.

Finally, PEFR values predicted by our model were plotted against age and compared with values from equations obtained from other studies in Africa, assuming a height of $164 \mathrm{~cm}$ for males and $155 \mathrm{~cm}$ for females (i.e. the median heights in our study).

Selection of healthy subjects

Prediction models were restricted to healthy individuals, defined as those who had not had: (i) a cold, a sore throat or discharge from the ears for the previous 4 weeks; (ii) a cough lasting for 1 month or more; and (iii) wheezing in the chest. Smokers and HIV-positive individuals were included, provided they satisfied the symptom requirements mentioned above. The analysis was restricted to adults aged $\geq 15$ years to be consistent with other studies in adults. ${ }^{[3]}$

\section{Ethical considerations}

The GPC has ethical approval (renewed annually) from the Uganda Virus Research Institute (UVRI) Science and Ethics Committee, ref. GC 127, and is also covered in the approval of 'General MRC Research Programme' by the National Council of Science and Technology (NCST) dated 15 October 1997, ref. MV 279/2 as 'Population Dynamics of HIV-1 transmission'.

\section{Results}

Study population

A total of 2904 subjects were resident in the study area and consented to participate in the medical survey; of these, 2505 were aged $\geq 15$ years. A total of 710 subjects were excluded from the PEFR prediction models on account of having respiratory symptoms at the time, 175 on account of failing to perform the PEFR test correctly and a further 65 had

Table 2. Predicted normal PEFR values for varying age and height by gender

\begin{tabular}{lccc}
\hline & \multicolumn{3}{c}{ Height $(\mathbf{c m})$} \\
\cline { 2 - 4 } Age (years) & $\mathbf{1 5 0}$ & $\mathbf{1 6 0}$ & $\mathbf{1 7 0}$ \\
\hline Males & & PEFR (L/minute) \\
15 & 439.1 & 477.2 & 513.6 \\
25 & 484.5 & 526.6 & 566.8 \\
35 & 485.2 & 527.3 & 567.5 \\
45 & 463.3 & 503.6 & 542.0 \\
55 & 430.1 & 467.5 & 503.2 \\
Females & & & \\
15 & 416.5 & 431.5 & 445.2 \\
25 & 426.7 & 442.2 & 456.2 \\
35 & 413.8 & 428.7 & 442.4 \\
45 & 390.6 & 404.7 & 417.5 \\
55 & 362.8 & 375.9 & 387.8
\end{tabular}


incomplete data on age or height. Therefore, there were 1555 people (774 male, 781 female) in the study population, of which 665 (42.8\%) were aged under 25 years and only 100 (6.4\%) aged $\geq 65$ years (Table 1 ). The median height was $164 \mathrm{~cm}$ (males) and $155 \mathrm{~cm}$ (females). This was in agreement with the population distribution in the area. The majority of participants had never smoked (males 76.7\%, females $98.3 \%$ ). Most participants (85\%) lived in houses with floor material made of ordinary murram (laterite), indicating low socioeconomic status.

When a comparison was made between medical survey participants and the GPC census participants, there was $50-60 \%$ participation in the medical survey for all age groups. Participation rates in the medical survey were slightly lower among males compared with females, but the differences were not significant.

\section{The PEFR prediction equations}

The equation that gave the best fit of the data for males was:

$\log _{e}$ PEFR $=6.188-0.019$ age $+0.557 \log _{e}$ age - 199.945/height

For females the equation was:

$\log _{\mathrm{e}} \mathrm{PEFR}=5.948-0.014$ age $+0.317 \log _{\mathrm{e}}$ age - 85.147/height

Table 2 shows normal predicted PEFR values with varying age and height for both males and females, obtained using the PEFR prediction equations generated in this study. For both males and females, predicted PEFR at 15 and 55 years was lower than predicted PEFR from 25 to 45 years.

Fig. 1 shows the observed values of PEFR in males and females plotted against age. The figure also shows the regression of PEFR on age for males of median height $164 \mathrm{~cm}$ and females of $155 \mathrm{~cm}$. The maximum value of PEFR occurred at around 30 years for males and 25 years for females. For both males and females, there was a steady reduction in PEFR with increasing age after the maximum value of PEFR was attained. Of the variability in PEFR, $43 \%$ was explained by the prediction equation for males, and $28 \%$ by the equation for females.

Fig. 2 shows the predicted values of PEFR for males of height $164 \mathrm{~cm}$ and females of height $155 \mathrm{~cm}$, compared with those obtained from three other studies in Africa. ${ }^{[3,9,10]}$

\section{Discussion}

In this study, the regression equations for predicting PEFR in a Ugandan population considering the changing trends of PEFR

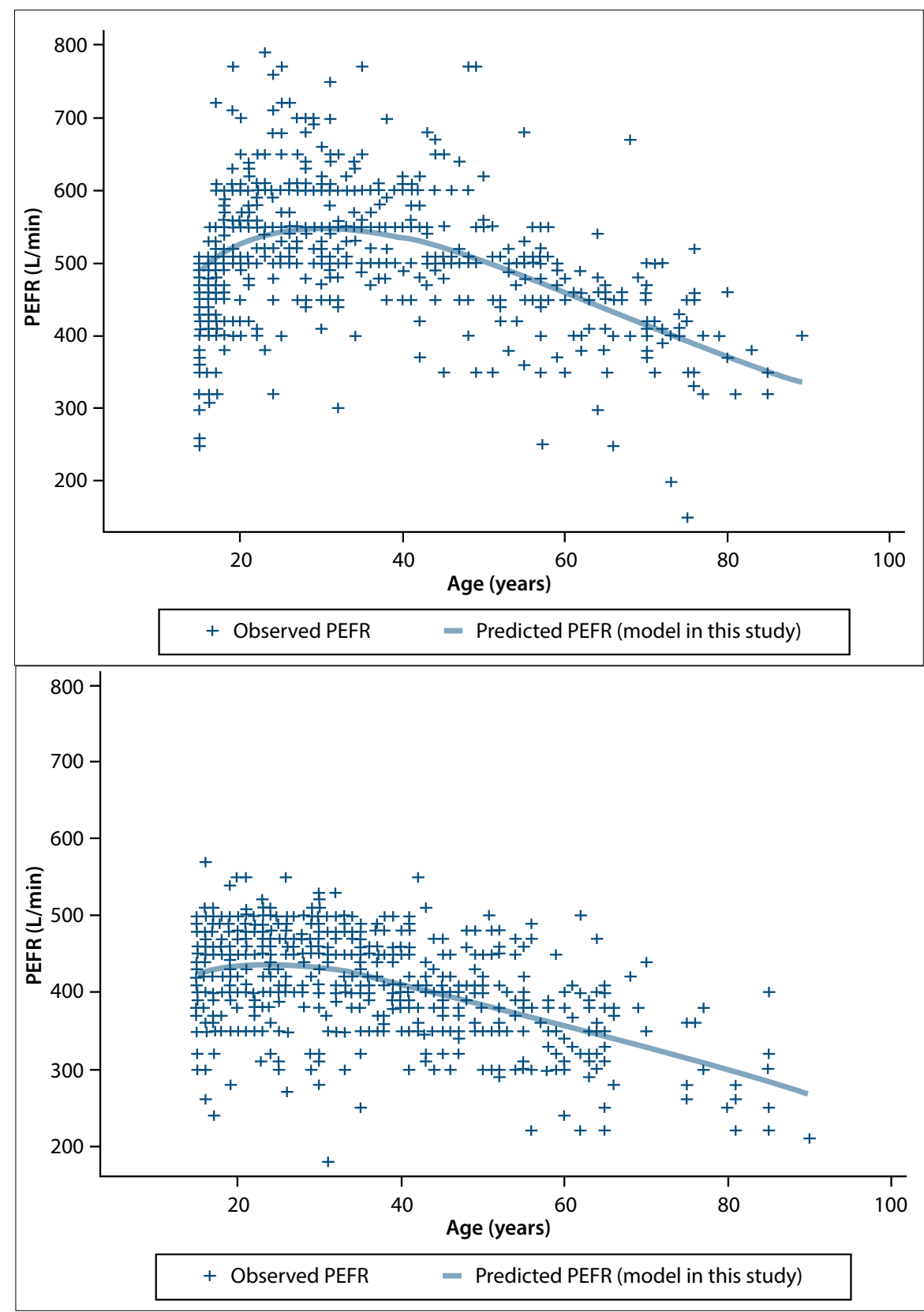

Fig. 1. Observed and predicted PEFR in males of median height of $164 \mathrm{~cm}$ (top) and females median height of $155 \mathrm{~cm}$ (bottom).

with age were generated for both males and females. Our equations could be used to derive nomograms of normal reference ranges for East African populations.

The regression equations developed in our study are similar to those from a study in Nigerian adults, because both assumed a curvilinear prediction model accounting for increasing PEFR in adolescence followed by a decline for older age groups. ${ }^{[3]}$ For both studies, maximum PEFR was reached at around 30 years for males and 25 years for females before declining in older age groups. ${ }^{[3]}$ However, our study differs from an earlier study on Sudanese, South Sudanese and Tanzanian males, ${ }^{[10]}$ which failed to recognise the increase in PEFR in adolescence and early adulthood, and a study on Sudanese persons, ${ }^{[9]}$ which also assumed a linear relationship for age 20 and above.

Our study found $43 \%$ of the variability in PEFR in males was explained by differences in age and height, in contrast to a study on Europeans where only $30 \%$ of the variability could be explained by age and height. However, for females, $28 \%$ of the PEFR variability was explained by age and height, which was similar to that reported among Europeans. ${ }^{[12]}$

A strength of our study is the large number of individuals included in our survey, which is well in excess of what 

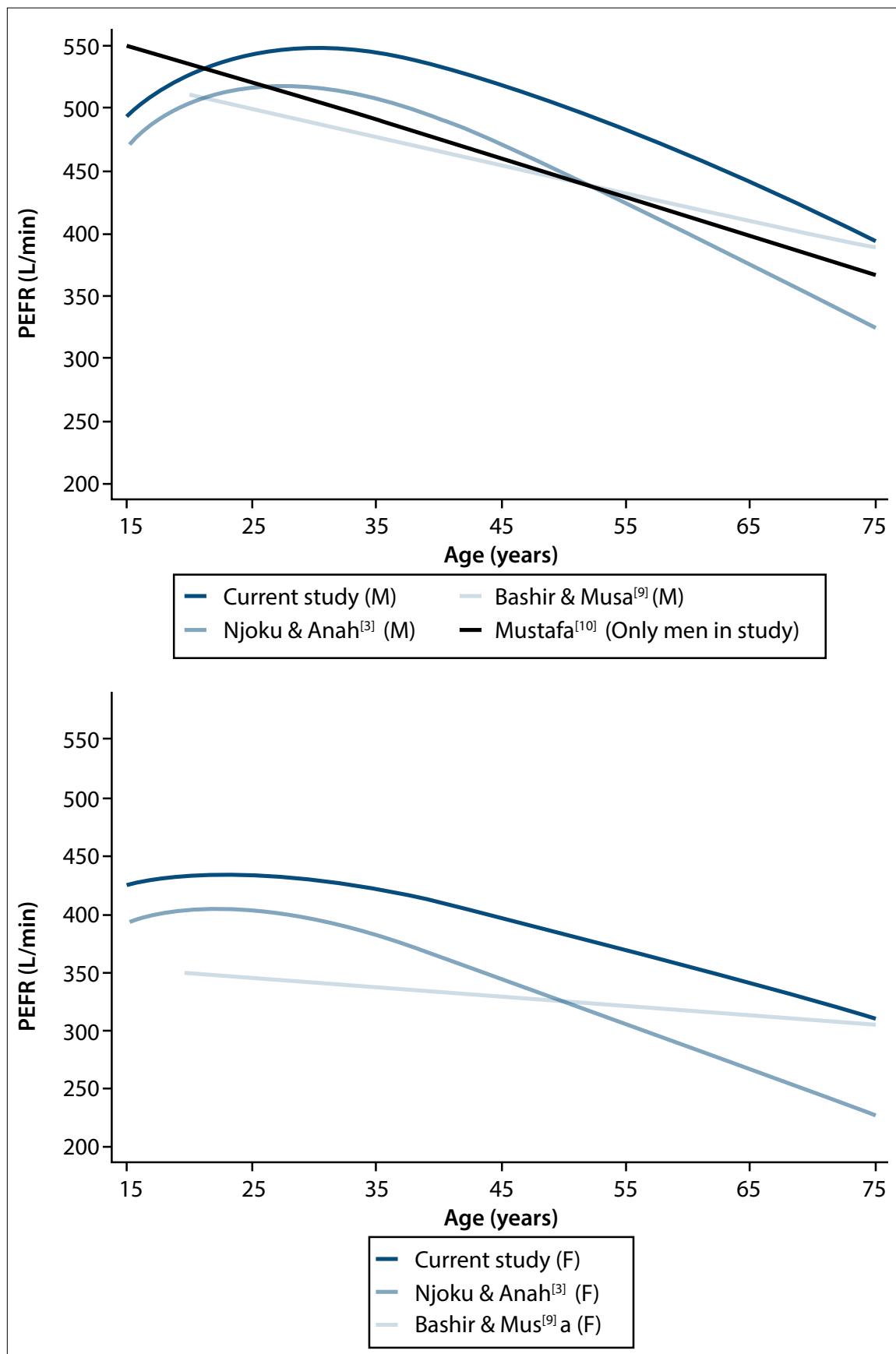

Fig. 2. Predicted PEFR for males (top) and females (bottom) comparing different studies, based on the median height of $164 \mathrm{~cm}$ and $155 \mathrm{~cm}$, respectively.

has been obtained in other published studies. ${ }^{[4,7]}$ However, there may be some limitations, such as under-representation within age groups due to absence or refusal to participate. It is also possible we may have missed individuals who were healthier, if they were more likely to be working away from home or travelling, and that individuals who were sicker were more likely to be found at home. Another possible limitation was the low representation of the older age groups when obtaining the prediction equations. Our total sample size for older participants was small, with only 64 males and 36 females aged 65 years or more in the analysis; therefore, our prediction equations may not be reliable for the older age groups.

\section{Conclusion}

In conclusion, this study has provided PEFR prediction equations that could be used in obtaining normal PEFR reference values for assessing basic respiratory function in East
African populations. A study in a different East African population would be of interest since it would help to confirm our findings. We will report in a different publication on the effects of smoking and other factors on PEFR.

Acknowledgements. This research was jointly funded by the UK Medical Research Council (MRC) and the UK Department for International Development (DFID) under the MRC/DFID Concordat agreement. We wish to acknowledge the study participants from the MRC General Population Cohort and staff of MRC/UVRI Uganda unit.

\section{References}

1. Quanjer PH, Stanojevic S, Cole TJ, et al. Multi ethnic reference values for spirometry for the 3 - 95-year age range: The global lung function 2012 equations. Euro Resp J 2012;40(6):1324-1343. [http://dx.doi. org/10.1183/09031936.00080312]

2. Altalag ARJ, Wilcox P, eds. Pulmonary Function Tests in Clinical Practice. London, UK: Springer-Verlag Limited, 2009:1-3.

3. Njoku CH, Anah CO. Reference values for peak expiratory flow rate in adults of African descent. Trop Doct 2004;34(3):135-140.

4. Teklu B, Sexona T, Mills RJ. Peak expiratory flow in normal Ethiopian children and adults in Addis Ababa. Br J Dis Chest 1987;81(2):176-181.

5. Bakki B, Hammangabdo A, Talle MA, Oluwole S, Yusuph H, Alkali MB. Peak expiratory flow in normal medical students in Maiduguri, Borno State, Nigeria. Pan Afr Med J 2012;12:73.

6. Musafiri S, van Meerbeeck JP, Musango L, et al. Spirometric reference values for an East African population. Respiration; international review of thoracic diseases. 2013;85(4):297-304. [http://dx.doi. org/10.1159/000337256]

7. Mengesha YA, Mekonnen Y. Spirometric lung function tests in normal non-smoking Ethiopian men and women. Thorax 1985;40(6):465-468.

8. Nku CO, Peters EJ, Eshiet Al, Bisong SA, Osim EE. Prediction formulae for lung function parameters in females of South Eastern Nigeria. Niger J Physiol Sci 2006;21(1-2):43-47.

9. Bashir AA, Musa OA. Reference spirometric values in a Sudanese cohort. East Mediterr Health J 2012;18(2):151-158.

10. Mustafa KY. Spirometric lung function tests in normal men and African ethnic origin. Am Rev Respir Dis. 1977;116(2):209-213.

11. Gregg I, Nunn AJ. Peak expiratory flow in normal subjects. BMJ 1973;3(5874):282-284.

12. Nunn AJ, Gregg I. New regression equations for predicting peak expiratory flow in adults. BMJ 1989;298(6680):1068-1070.

13. Kazooba P, Kasamba I, Baisley K, Mayanja BN, Maher D. Access to, and uptake of, antiretroviral therapy in a developing country with high HIV prevalence: A population-based cohort study in rural Uganda, 2004 - 2008. Trop Med Int Health 2012;17(8):e49-57.

14. Asiki G, Murphy G, Nakiyingi-Miiro J, et al. The general population cohort in rural south-western Uganda: A platform for communicable and non-communicable disease studies. Int J Epidemiol 2013;42(1):129-141. [http://dx.doi.org/10.1093/ije/dys234] 